\title{
Which Large- and Medium-Sized Mammals Use Commercial Short-Rotation Coppice as Habitat?
}

\author{
Felix Zitzmann ${ }^{1}$ (D) $\cdot$ Michael Reich ${ }^{1}$ (D)
}

Received: 13 July 2021 / Accepted: 6 October 2021 / Published online: 11 January 2022

(c) The Author(s) 2022

\begin{abstract}
We surveyed occurrence and activity of large- and medium-sized mammals on six commercial mini-rotation short-rotation coppice (SRC) plantations in northern Germany by camera trapping in different seasons (winter, late summer). In total, eleven species (6-9 per site) were detected. This corresponds to the majority of mammal species occurring in the study region. Roe deer, wild boar and red fox were found across all sites. All other species were detected on fewer sites and some in only one of the seasons. Roe deer was the most active species both in terms of visit frequency (days with detection) and use intensity (detection numbers). With few exceptions on individual sites, all other species showed significantly lower activity. Number of detected species and activity of most of the species did not differ between seasons. Furthermore, there were no differences between near-edge and central areas of the crops with regard to the activity of the occurring species. Activity of individual species on different sites, however, differed considerably in some cases. Our results show that a wide range of mammal species are basically able to include SRC into their habitat utilisation. However, the sporadic use by most species indicates a rather limited current habitat value of the surveyed plantations. Options to increase the habitat value of SRC for mammals are suggested, but their effectiveness needs to be tested in future studies. Since the spatial and temporal scope of our study was limited and only SRC of a uniform age-class were considered, our results are not immediately applicable to other landscapes, seasons or types and management phases of SRC. Therefore, further research is required that considers these aspects as well as species-specific patterns of habitat selection in comparison to other habitat types.
\end{abstract}

Keywords Perennial woody biomass crops $\cdot$ Biodiversity $\cdot$ Wildlife $\cdot$ Game $\cdot$ Camera trapping

\section{Introduction}

Short-rotation coppices (SRC) are perennial biomass crops consisting of fast-growing deciduous trees which are harvested in short cycles. Depending on the intended utilisation, harvesting can be carried out in short ( $2-5$ years), medium (6-12 years) and long (12-20 years) intervals [1]. In order to produce dendromass for energy purposes, the plantations are usually harvested in short cycles (so-called mini-rotation) and are established with densities of 7,000-16,000 stools per ha $[1,2]$. Due to their characteristics, a number of different tree species are generally suitable for cultivation in mini-rotation SRC and are also permissible under subsidy law in the European Union [3]. However, in Europe and

Felix Zitzmann

zitzmann@umwelt.uni-hannover.de

1 Institute of Environmental Planning, Leibniz University Hannover, Herrenhäuser Str. 2, 30419 Hannover, Germany particularly in Germany, varieties of the genera poplar (Populus) and willow (Salix) are most common and widely used for cultivation in mini-rotation SRC $[1,2]$.

Since SRC differ substantially from previously established annual arable crops with regard to their management and their habitat characteristics [4], they can offer opportunities to improve spatial and structural heterogeneity in agroecosystems by providing areas of tall and dense perennial crops with low mechanical and chemical input [5-9]. Previous studies on biodiversity of these woody biomass crops for various species groups, such as breeding birds or vascular plants, have shown that SRC can contribute to increased biodiversity, especially in intensively used agricultural landscapes [7, 10-12]. However, large and medium-sized mammals as an important component of farmland biodiversity have hardly been considered in these studies. The few existing studies are either based on the detection of characteristic tracks or merely document accidental observations [see 13-17]. Merely the results of a camera trapping survey by 
Zitzmann et al. [18] provide a first insight into the spatiotemporal utilisation of SRC by mammal species in different seasons. However, this study was conducted on experimental SRC where different tree species and age-classes were present simultaneously within the same plantation. These structurally diverse experimental sites do not have much in common with the commercial cultivation of SRC in terms of their habitat structure and their management. Therefore, knowledge about the habitat quality and the spatio-temporal utilisation of commercial SRC by different mammal species is still limited. Considering a further expansion of SRC cultivation in Europe, an adequate understanding of the impact of these biomass crops on all components of farmland biodiversity is essential for preventing potential future conflicts with biodiversity and other ecosystem services and for maximising environmental benefits from these crops $[6,8,19]$. Therefore, the aims of our investigation were to determine:

1. Which mammal species incorporate commercial minirotation SRC into their habitat utilisation

2. How frequently and intensively these crops are used by those species in different seasons

3. Whether there are seasonal differences in mammalian activity on these plantations

4. Whether there are differences in mammalian occurrence and activity between different areas within the crops (from close to the edge to the crop-centre).

Based on our findings, options for a wildlife-friendly cultivation and management of SRC are discussed, and further research demand is identified.

\section{Materials and Methods}

\section{Study Area and Study Sites}

Surveys were conducted on six mini-rotation SRC in the municipality of Soltau (Heidekreis district, Lower Saxony) in northern Germany. The study region is a rural area characterised by agriculture and forestry. The proportion of agricultural land (predominantly used as arable land) in the district exceeds $40 \%$; the woodland proportion is about $30 \%$ and thus corresponds roughly to the national average but is quite high for northern Germany [20].

In the study region, a relatively high amount of SRC existed at the time of the study, which had been established within the last 15 years. Therefore, SRC cultivation in this region exceeds the widespread experimental cultivation on single pilot sites with different tree species per site and section-wise harvesting and represents a more commercial cultivation practice. For our investigation, we only considered plantations that represented commercial mini-rotation
SRC in terms of their structural characteristics. Therefore, the following criteria were defined for the selection of suitable study sites: (i) unfenced SRC sites or stands (i.e. units of larger plantations) of at least 1 ha in size, without any internal structures such as rides or clearings; (ii) max. $10 \%$ tree-failures; (iii) the entire area of the site/stand belongs to the same age-class and is cultivated with trees of the same genus (Salix or Populus) and (iv) the last harvest or the establishment of the site/stand was not less than 2 years nor more than 5 years ago. These criteria represent the structural characteristics of commercially used mini-rotation SRC (with rotation lengths of 2-5 years) during the majority of their rotation cycle [cf. 4].

Out of 13 existing SRC in the region that met these criteria, six sites were randomly chosen. This included five willow plantations and one poplar plantation each of a size between 1 and 7 ha (Table 1). All of the studied sites had already been harvested several times since their establishment and, therefore, had a dense and shrubby vegetation structure with numerous shoots per stool. At the time of the study, trees within the study sites were 3-7 $\mathrm{m}$ high and the last harvest had taken place 3-5 years ago. Willows were planted at a density of 12,000 stools/ha and poplars at 9,000 stools/ha; due to failures of 5 to max. $10 \%$ of the trees, the actual stool density was slightly lower. The distance between the individual sites or stands was at least $150 \mathrm{~m}$ and max. $4 \mathrm{~km}$.

\section{Detection of Mammals at the Study Sites}

We used 18 camera traps (CTs) which were automatically triggered by motion and infrared-sensors once an animal of sufficient size was present within the detection area [cf. 21,22]. Three CTs, either "Dörr Snapshot Limited Black 5.0S" or "Dörr Snapshot Extra 5.0 MP" models, were installed at each site. Both models are able to record at night and at dawn and are almost identical in terms of their basic technical features.

Table 1 Characteristics of the study sites

\begin{tabular}{lrlll}
\hline Site & Position & Area (ha) & Cultivated clones & Height \\
\hline A & $52^{\circ} 57^{\prime} 20.6^{\prime \prime} \mathrm{N}$ & 1.7 & Salix Inger & $3-5 \mathrm{~m}$ \\
& $9^{\circ} 48^{\prime} 23.4^{\prime \prime} \mathrm{E}$ & & & \\
$\mathrm{B}$ & $52^{\circ} 56^{\prime} 49.8^{\prime \prime} \mathrm{N}$ & 2.0 & Poplar Hybride 275 & $5-7 \mathrm{~m}$ \\
& $9^{\circ} 48^{\prime} 58.4^{\prime \prime} \mathrm{E}$ & & & \\
$\mathrm{C}$ & $52^{\circ} 56^{\prime} 59.5^{\prime \prime} \mathrm{N}$ & 7.0 & Salix Tordis/Sven & $5-6 \mathrm{~m}$ \\
& $9^{\circ} 45^{\prime} 03.0^{\prime \prime} \mathrm{E}$ & & & \\
$\mathrm{D}$ & $52^{\circ} 57^{\prime} 19.5^{\prime \prime} \mathrm{N}$ & 1.2 & Salix Inger & $4-5 \mathrm{~m}$ \\
& $9^{\circ} 48^{\prime} 10.6^{\prime \prime} \mathrm{E}$ & & & \\
$\mathrm{E}$ & $52^{\circ} 57^{\prime} 22.1^{\prime \prime} \mathrm{N}$ & 4.8 & Salix Tordis & $5-7 \mathrm{~m}$ \\
& $9^{\circ} 48^{\prime} 48.8^{\prime \prime} \mathrm{E}$ & & & \\
$\mathrm{F}$ & $52^{\circ} 57^{\prime} 34.1^{\prime \prime} \mathrm{N}$ & 3.9 & Salix Inger/Tora & $3-5 \mathrm{~m}$ \\
& $9^{\circ} 48^{\prime} 30.0^{\prime \prime} \mathrm{E}$ & & & \\
\hline
\end{tabular}


Surveys were carried out from November 2019 to January 2020 (84 days) in winter and during August and September (62 days) the following summer. Due to technical defects or empty batteries, there were temporary failures of individual CTs in both seasons, so the number of active camera days per CT varied slightly (Table 2 ).

At each site, three CTs of the same model were set up in a line transect running from the edge of the crop towards its centre. The starting point of the line transect was randomly selected. All three CTs were set up within the crops. The first CT was positioned at a distance of $5 \mathrm{~m}$, the second at a distance of $25 \mathrm{~m}$ and the third at a distance of $50 \mathrm{~m}$ from the outer crop-edge. In both seasons, the positioning of the three CTs at the individual sites remained the same. The CTs were placed between tree rows and aligned so that the area between the rows could be observed. All three CTs used per site were oriented in the same direction. The CTs were attached to poles so that the camera lens was at a height of $50 \mathrm{~cm}$. The time tag was activated in order to document the date and time of the individual detections. The number of images created per trigger was set to three; thus, a series of three consecutive images was generated during one triggering event. This facilitates the subsequent identification of species based on the photographic material. The delay between two triggers was set to $5 \mathrm{~s}$, i.e. retriggering was possible $5 \mathrm{~s}$ after the previous trigger. Sensitivity of the motion sensor was set to high. CTs were active continuously, i.e. no time window was set. Cameras were controlled every 3 to 4 weeks.

\section{Data preparation and Statistical Analysis}

After finishing camera trapping, the information (date, time, site, position of the CT, detected species) gathered from the images of visible large and medium-sized mammals was transferred into a table for further statistical analysis. Thereby, each table row represents one detection event, i.e. a series of three consecutive images resulting from one trigger (see CT settings). Only images with mammal species of at least the size of a red squirrel (Sciurus vulgaris) were taken into account. Images of smaller mammals (mostly Muroidea, but also other small mammals such as the least weasel Mustela nivalis) were excluded from any further consideration, as were images without any visible mammal species, images of domestic mammals or birds and human-induced images.
Species number per site $(n=6)$ and per CT $(n=18)$, as well as species number per CT per camera day, was determined for each season. In addition, the proportion of the species-specific detections was calculated for the different seasons and sites. Furthermore, the two following indices were calculated as indicators for the activity of the different mammal species at the study sites:

- The number of detections per CT in relation to $100 \mathrm{cam}$ era days [cf. 21] was used as an indicator for the use intensity [23]. It was calculated by: (no. of detections per CT / no. of active camera days per CT) $\times 100$. The value was calculated for the individual species and also cumulatively for all species together.

- The proportion of days that a particular species had been detected was considered as an indicator for the visit frequency [23] and was calculated by: (no. of days with presence of the species $\times 100$ ) / no. of active camera days. The index was calculated per CT and per study site (i.e. as an aggregated value of the three CTs used per site).

For all these calculations, one camera day was defined as a 24-h period beginning and ending at 12 a.m., thus encompassing the entire dawn and night time as the main activity period for the most mammal species.

Variables were tested for differences between the three distance-classes ( $5 \mathrm{~m}, 25 \mathrm{~m}, 50 \mathrm{~m}$ with $n=6$ per type) using the Friedman-Test, with the Dunn-Bonferroni-test as a post hoc test. The comparison of mammalian activity between the seasons (summer and winter) was performed using the Wilcoxon signed rank test. Therefore, the individual CTs ( $n=18$ per season) were used as related samples. All statistical analyses were performed using IBM SPSS Statistics version 26.

\section{Results}

\section{Detected Species and Number of Detections}

In winter (84 days), a total of 735 detections $(50.4 \pm 34.3$ per CT) of large and medium-sized mammals were made by the 18 CTs over 1,403 camera days (Appendix: Table 5). In summer (62 days), a total of 1,164 detections (109.4 \pm 93.7 per CT) were made over 1,050 camera days.

Table 2 Survey periods in the different seasons

\begin{tabular}{lllll}
\hline Season & Survey period & No. of days & $\begin{array}{l}\text { Mean no. of camera days per } \\
\text { CT }( \pm \text { SD })\end{array}$ & Total no. of camera days \\
\hline Winter & 5 November 2019-28 January 2020 & 84 & $77.9 \pm 13.3$ & 1,403 \\
Summer & 30 July-30 September 2020 & 62 & $58.3 \pm 9.2$ & 1,050 \\
\hline
\end{tabular}


In total, eleven species were detected across all sites, each ten in winter and ten in summer. For each site, 5-8 species were detected in winter, 3-9 species in summer and 6-9 species when both seasons are combined (Table 3). Roe deer Capreolus capreolus and red fox Vulpes vulpes were recorded across all sites in both seasons, and wild boar Sus scrofa was detected across all sites in winter and at five of the six sites in summer. The European hare Lepus europaeus was recorded at four sites in both seasons. European badger Meles meles, raccoon dog Nyctereutes procyonoides and beech marten Martes foina were each detected at two to four sites in each season. Fallow deer Dama dama occurred at only one site in winter, but at four sites in summer. The three remaining species were only sporadically recorded at one single site in both seasons (raccoon Procyon lotor) or at one or two sites in only one season (European polecat Mustela putorius, red squirrel Sciurus vulgaris).

In both seasons, roe deer accounted for more than half (winter: 54\%, summer: 61\%) of all detections made (Appendix: Table 5), followed by wild boar with $18 \%$ in each season. All other species had lower proportions of $<10 \%$, in many cases even $<2 \%$ of the total number of detections made in the different seasons. At the individual sites, roe deer also mostly accounted for the largest proportion of

Table 3 Visit frequency of the different species at the study sites in winter (W) and in summer (S). The visit frequency is given as an aggregated value of the three CTs used per site

\begin{tabular}{|c|c|c|c|c|c|c|c|}
\hline \multirow{2}{*}{ Species name } & & \multicolumn{6}{|c|}{ Visit frequency $^{1}$ per study site [in $\%$ of days] } \\
\hline & & $\mathrm{A}$ & $\mathrm{B}$ & $\mathrm{C}$ & $\mathrm{D}$ & $E$ & $\mathrm{~F}$ \\
\hline \multirow{2}{*}{$\begin{array}{l}\text { Roe deer } \\
\text { Capreolus capreolus }\end{array}$} & W & 29.8 & 51.2 & 11.9 & 17.9 & 5.8 & 9.5 \\
\hline & $\mathrm{S}$ & 27.4 & 66.1 & 25.8 & 12.9 & 33.9 & 4.8 \\
\hline \multirow{2}{*}{$\begin{array}{l}\text { Wild boar } \\
\text { Sus scrofa }\end{array}$} & W & 1.2 & 7.1 & 7.1 & 1.2 & 10.1 & 10.7 \\
\hline & $\mathrm{S}$ & 6.5 & 8.1 & 9.7 & 4.8 & 21.0 & \\
\hline \multirow{2}{*}{$\begin{array}{l}\text { Red fox } \\
\text { Vulpes vulpes }\end{array}$} & W & 10.7 & 15.5 & 4.8 & 6.0 & 5.8 & 7.1 \\
\hline & $\mathrm{S}$ & 3.2 & 4.8 & 4.8 & 1.6 & 3.2 & 3.2 \\
\hline \multirow{2}{*}{$\begin{array}{l}\text { Europ. hare } \\
\text { Lepus europaeus }\end{array}$} & W & & 22.6 & 3.6 & 7.1 & 1.4 & \\
\hline & $\mathrm{S}$ & & 3.2 & 1.6 & 4.8 & 1.6 & \\
\hline \multirow{2}{*}{$\begin{array}{l}\text { Europ. badger } \\
\text { Meles meles }\end{array}$} & W & 3.6 & 9.5 & 9.5 & & 2.9 & \\
\hline & $\mathrm{S}$ & 1.6 & 41.9 & & & 6.5 & \\
\hline \multirow{2}{*}{$\begin{array}{l}\text { Raccoon dog } \\
\text { Nyctereutes procyonoides }\end{array}$} & W & 1.2 & 1.2 & & & 1.4 & 4.8 \\
\hline & $\mathrm{S}$ & & 1.6 & 1.6 & & & \\
\hline \multirow{2}{*}{$\begin{array}{l}\text { Beech marten } \\
\text { Martes foina }\end{array}$} & W & & & & 1.2 & 1.4 & \\
\hline & $\mathrm{S}$ & & 4.8 & 1.6 & & 1.6 & \\
\hline \multirow{2}{*}{$\begin{array}{l}\text { Raccoon } \\
\text { Procyon lotor }\end{array}$} & W & & & 6.0 & & & \\
\hline & $\mathrm{S}$ & & & 1.6 & & & \\
\hline \multirow{2}{*}{$\begin{array}{l}\text { Fallow deer } \\
\text { Dama dama }\end{array}$} & W & & & 4.8 & & & \\
\hline & $\mathrm{S}$ & 1.6 & 1.6 & 17.7 & 1.6 & & \\
\hline \multirow{2}{*}{$\begin{array}{l}\text { Red squirrel } \\
\text { Sciurus vulgaris }\end{array}$} & W & & & & & & \\
\hline & $\mathrm{S}$ & & 1.6 & & & 1.6 & \\
\hline \multirow{2}{*}{$\begin{array}{l}\text { Europ. polecat } \\
\text { Mustela putorius }\end{array}$} & W & & & & & & 1.2 \\
\hline & $\mathrm{S}$ & & & & & & \\
\hline \multirow{2}{*}{ Genus Martes } & W & & & 1.2 & 3.6 & 1.4 & \\
\hline & $\mathrm{S}$ & & & & 1.6 & 3.2 & 1.6 \\
\hline \multirow{2}{*}{$\begin{array}{l}\text { Genust Martes } \\
\text { or Mustela }\end{array}$} & W & & & & & & 1.2 \\
\hline & $\mathrm{S}$ & & & & & 1.6 & \\
\hline \multirow{2}{*}{$\begin{array}{l}\text { No. of days } \\
\text { per season }\end{array}$} & $\mathrm{W}$ & 84 & 84 & 84 & 84 & 69 & 84 \\
\hline & $\mathrm{S}$ & 62 & 62 & 62 & 62 & 62 & 62 \\
\hline \multirow{2}{*}{$\begin{array}{l}\text { No. of species } \\
\text { per season }\end{array}$} & W & 5 & 6 & 8 & 5 & 7 & 5 \\
\hline & $\mathrm{S}$ & 5 & 9 & 8 & 6 & 7 & 3 \\
\hline $\begin{array}{l}\text { Total no. of species } \\
\text { (both seasons) }\end{array}$ & & 6 & 9 & 9 & 6 & 8 & 6 \\
\hline
\end{tabular}

${ }^{1}$ Visit frequency=Proportion of days [\%] with detection of the particular species by at least one of the three CTs used per site

${ }^{2}$ No. of days per season=No. of days on which at least one of the three CTs used per site was active 
detections. However, on some sites, wild boar made up the largest proportion. All other species had much lower proportions at almost all sites, with most significantly $<10 \%$ of the site-specific detections. The species-specific proportions of detections varied considerably between the different sites. Especially the proportions for roe deer $(12-87 \%$ of all detections per site) and wild boar (1-59\%) varied greatly, indicating large differences in the intensity of habitat use between different sites.

In both seasons, $2-3 \%$ of the detections could not be determined due to poor image quality. In addition, some detections with representatives of the genus Martes or Mustela could not be determined to species level due to inadequate image quality. These detections were only taken into account for the calculation of species numbers if no clear detections of beech marten or European polecat were made at the respective site (respectively on the particular day when calculating the variable "mean no. of species per CT per camera day"; see Table 4).

\section{Visit Frequency}

Roe deer used the majority of sites most frequently in both seasons (Table 3). Only at sites E and F wild boars were recorded on slightly more days than roe deer, but this only occurred during the winter season. The proportion of days with detections of the different species varied considerably between the study sites and also between the seasons. For example, roe deer were detected on two-thirds of the days surveyed in summer at site B, but only every 20 th day (5\%) at site F. Except for the roe deer, most species were detected on only a few days (max. 11\%) at the individual sites, many of them even on just one single day (1.2-1.6\%). In only a few cases single species were detected more frequently at individual sites (badger on site B in summer, hare and red fox on site B in winter, wild boar on site $\mathrm{E}$ in summer, fallow deer on site $\mathrm{C}$ in summer).

\section{Seasonal Activity Patterns}

There were no differences between the two seasons with regard to the number of species detected per CT per day (Table 4). Except for the red fox, which was detected more frequently in winter, and for the fallow deer, which was detected more frequently in summer, there were no differences with regard to the visit frequency between the seasons for any of the species tested. With regard to the use intensity (i.e. the no. of detections per 100 camera days), there were no differences between the two seasons for six of the nine species considered. For three species, however, there were differences with regard to this variable: roe deer and fallow deer showed significantly higher use intensity in summer, whereas the use intensity of the red fox was significantly
Table 4 Mean values $( \pm$ SD) of the measured variables per CT in the different seasons (with $n=18$ CTs used per season). Differences between the seasons were tested by Wilcoxon test. Significantly greater values are marked in bold

\begin{tabular}{lccll}
\hline Variable & Winter & Summer & Test statistics & $p$ \\
\hline $\begin{array}{l}\text { No. of species } \\
\text { per camera }\end{array}$ & $0.22 \pm 0.16$ & $0.27 \pm 0.24$ & -1.111 & $0.266 \mathrm{n} . \mathrm{s}$ \\
$\quad$ day & & & & \\
Visit frequency & & & & \\
All species & $19.5 \pm 11.5$ & $23.9 \pm 19.5$ & -1.198 & $0.231 \mathrm{n} . \mathrm{s}$ \\
Roe deer & $9.8 \pm 9.5$ & $13.2 \pm 12.3$ & -0.781 & $0.435 \mathrm{n} . \mathrm{s}$ \\
Wild boar & $2.7 \pm 2.2$ & $3.4 \pm 4.3$ & -0.450 & $0.653 \mathrm{n} . \mathrm{s}$ \\
Red fox & $\mathbf{3 . 4} \pm \mathbf{2 . 1}$ & $1.2 \pm 1.1$ & -2.921 & $0.003^{*}$ \\
Europ. hare & $2.5 \pm 4.0$ & $1.0 \pm 1.5$ & -1.601 & $0.109 \mathrm{n} . \mathrm{s}$ \\
Europ. badger & $1.7 \pm 2.1$ & $4.6 \pm 9.9$ & -0.712 & $0.476 \mathrm{n} . \mathrm{s}$ \\
Raccoon dog & $0.5 \pm 1.2$ & $0.2 \pm 0.6$ & -0.315 & $0.752 \mathrm{n} . \mathrm{s}$ \\
Beech marten & $0.1 \pm 0.4$ & $0.5 \pm 1.0$ & -1.483 & $0.138 \mathrm{n} . \mathrm{s}$ \\
Raccoon & $0.4 \pm 1.2$ & $0.1 \pm 0.4$ & -1.633 & $0.102 \mathrm{n} . \mathrm{s}$ \\
Fallow deer & $0.3 \pm 0.9$ & $\mathbf{1 . 5} \pm \mathbf{2 . 7}$ & -2.207 & $0.027^{*}$ \\
Use intensity & & & & \\
All species & $50.4 \pm 34.3$ & $\mathbf{1 0 9 . 4} \pm \mathbf{9 3 . 7}$ & -2.678 & $0.007^{*}$ \\
Roe deer & $26.4 \pm 26.2$ & $\mathbf{6 6 . 9} \pm \mathbf{6 8 . 9}$ & -2.249 & $0.025^{*}$ \\
Wild boar & $9.3 \pm 12.8$ & $19.6 \pm 50.6$ & -0.355 & $0.723 \mathrm{n} . \mathrm{s}$ \\
Red fox & $\mathbf{3 . 7} \pm \mathbf{2 . 6}$ & $1.2 \pm 1.1$ & -2.917 & $0.004^{*}$ \\
Europ. hare & $3.9 \pm 7.4$ & $2.1 \pm 5.2$ & -1.364 & $0.173 \mathrm{n} . \mathrm{s}$ \\
Europ. badger & $2.4 \pm 3.1$ & $9.7 \pm 21.5$ & -0.845 & $0.398 \mathrm{n} . \mathrm{s}$ \\
Raccoon dog & $0.6 \pm 1.6$ & $0.4 \pm 1.2$ & -0.315 & $0.752 \mathrm{n} . \mathrm{s}$ \\
Beech marten & $0.1 \pm 0.4$ & $0.8 \pm 1.6$ & -1.483 & $0.138 \mathrm{n} . \mathrm{s}$ \\
Raccoon & $0.8 \pm 2.3$ & $0.5 \pm 1.9$ & -1.604 & $0.109 \mathrm{n} . \mathrm{s}$ \\
Fallow deer & $0.6 \pm 2.0$ & $\mathbf{5 . 3} \pm \mathbf{1 0 . 3}$ & -2.201 & $0.028^{*}$ \\
\hline
\end{tabular}

n.s. not significant; $* p<0.05$

${ }^{\mathrm{a}} \mathrm{Visit}$ frequency $=$ proportion of days [\%] with presence of the particular species per CT

${ }^{\mathrm{b}}$ Use intensity $=$ no. of detections per 100 camera days per CT

higher in winter. The aggregated value for the use intensity of all species combined was significantly higher in summer than in winter. However, the value was largely influenced by the comparatively high use intensity of roe deer in this season.

\section{Activity at Different Distances from the Crop-Edge to the Centre}

For all the species and variables tested, there were no differences between the three distance classes from the edge to the centre of the SRC in both seasons (Appendix: Tables 6 and 7). Thus, there were no differences with respect to the number of detected species (total no. of species and no. of species per camera day) between the three distance classes in both seasons. Furthermore, the different areas within the crop were used with a similar use intensity and visit frequency by the individual species, regardless of their distance 
from the edge and regardless of the season. Thus, within the six SRC studied, no clear preference for specific areas within the plantations could be discerned for any of the species detected. Instead, there was a relatively homogeneous utilisation across the entire site. The high standard deviation of some of the values indicates a high variability in use intensity and visit frequency between different sites and different CTs. This was already evident regarding the number of detections per site (Appendix: Table 5) and the visit frequency per site (Table 3 ).

\section{Discussion}

Basically, there are some factors to consider that limit the transferability of our results to other spatial and temporal situations as well as other types and management phases of SRC. Firstly, we specifically investigated mini-rotation SRC at a uniform age-class. Therefore, no conclusions on the influence of harvesting or longer rotation cycles on specific mammal species can be drawn on the basis of our study. In addition, the study period was limited to about half a year and therefore did not include all seasonal activity phases of mammals within the year. Moreover, all the plantations studied were located within the same region, so the species pool was limited to the species present in this region, and individual nearby plantations may have been used by the same individuals of certain species in some cases. Therefore, our results are not immediately applicable to other landscapes, mammal species and seasons, or to different age-classes and types of SRC. For this purpose, further research is required that includes SRC in its different variations (with regard to plantation size and shape, rotation length and cultivated tree species or varieties) across different landscapes and that covers several years and management stages. Nevertheless, the investigated sites represent the structural characteristics of commercially used mini-rotation SRC during the majority of their rotation cycle [cf. 4]. In addition, the study took place in a region where the majority of Germany's terrestrial large and medium-sized mammals occur (excluding species with only regional distribution, like from the Alpine region) and which roughly corresponds to the German average in terms of its proportion of land used for agriculture and forestry. The study therefore provides the first in-depth insight into the spatio-temporal use of commercial mini-rotation SRC by a wide range of different large- and medium-sized mammal species within a typical rural area in Germany, complementing previous unsystematic observations or indirect mammal detections on SRC by tracks [cf. 13-17].

The eleven species recorded on the surveyed SRC represent the majority of terrestrial large- and medium-sized mammal species distributed in northern Germany [24, 25]. Species with large territories that are quite rare in the region
(Eurasian wolf Canis lupus lupus, European wildcat Felis sylvestris and red deer Cervus elaphus) were not detected. Of the more common species, only pine marten Martes martes, European rabbit Oryctolagus cuniculus and European hedgehog Erinaceus europaeus were absent. However, the two latter species were detected during camera trapping surveys on other SRC in north-western Germany [18]. Furthermore, occurrence of the pine marten at the study sites cannot be excluded with certainty, as some images with representatives of the genus Martes could not be determined up to species level. Therefore, our results demonstrate that most of the common and widespread mammal species in Germany are able to use SRC as habitat. The study sites, however, were not used very frequently by most of these species. Some species occurred only at individual sites, only on a few days or in only one of the seasons. And even those species that were detected on the majority or all of the surveyed SRC (roe deer, red fox and wild boar, which are three of the most common and widespread mammal species in Germany and in the study region [25]) generally tended to use the plantations only sporadically, i.e. mostly on only a few days of the respective study period (see Table 3). This result is in line with the findings of Christian [13], who, during snowtracking studies on SRC in the USA, also found no evidence of either concentrated use or extensive avoidance of these plantations by various mammal species. Therefore, our results indicate that though many species were able to include the surveyed SRC in their habitat utilisation, the plantations did not represent a high-quality habitat which was frequently used by the most species or which strongly attracted mammal species [cf. 13]. A possible reason for this could be the availability of sufficient other, more important habitats in our study region. Therefore, there was probably little reason for most species to use the plantations more frequently. However, since we did not carry out simultaneous surveys in reference habitats, it is not possible to say where the animals spent the rest of the time and to what extent they included other habitat types in their habitat use. Future studies should therefore include reference habitats such as arable land (as the previous land-use of SRC) or forests to better understand patterns of species-specific habitat selection and preference for or avoidance of SRC by different mammal species in comparison to other habitat types. In this context, it should be determined whether SRC for mammals, as found for other species groups (e.g. breeding birds [26] or vascular plants $[27,28]$ ), have a higher habitat value in landscapes with reduced habitat diversity and availability (e.g. landscapes with high proportions of intensively used arable land and low proportions of woody habitats like forests, hedges or shrubs).

Although most of the surveyed plantations were used rather sporadically by the detected mammals, some species (such as roe deer, wild boar and badger) showed considerable 
differences with regard to their activity on different sites. Similar findings are also reported by Christian [13]. This indicates that there is apparently a strong effect of the immediate surrounding on the use of the crops by mammals, even in the case of nearby and structurally uniform SRC located in the same region. Thus, habitat composition and configuration within the immediate surrounding of a plantation seems to have a major impact on which species incorporate SRC in their habitat use and how frequently and intensively they use these crops [cf. 13]. Future studies should further investigate this effect on different mammal species. The results can be used to strategically influence the future utilisation by mammals when searching for a suitable location to establish new SRC. This would help to guide plantations to sites where their value as habitat for mammals or their attractiveness for certain mammal species is particularly high. At the same time, however, the crops could also be directed to sites where the use by certain species is minimised. This could, for example, mitigate conflicts caused by damage from deer species without the need to fence the crops.

A major finding from previous studies on biodiversity of SRC is that species diversity, activity and abundance, for some species groups (e.g. breeding birds, carabid beetles or vascular plants), decreases from the edge of the crops towards the centre [7, 29-33]. These patterns were not confirmed in our study for large- and medium-sized mammals. In both seasons, we did not detect any differences between different areas within the crops, neither in terms of the number of detected species nor for their activity (use intensity and visit frequency). Therefore, our results suggest that there is a relatively uniform utilisation of the entire plantation by mammal species within commercial mini-rotation SRC of a monotonous age-class. Camera trapping surveys by Zitzmann et al. [18] on experimental SRC sites, with stands of different tree species and age-classes in north-western Germany, demonstrated that these plantations were visited more frequently and used more intensively by common species, such as the European hare, than the commercial SRC surveyed in our study. The majority of hare detections (but also roe deer detections) within these structurally diverse SRC were made at the edge-zones between open areas (e.g. headlands, rides, harvested stands) and tree stands. Since hare densities in both regions are at a comparable level [24, $34,35]$, the structural characteristics of the SRC could have influenced the habitat quality for this species to a significant degree. Especially for open-land species such as the European hare, a species of conservation concern in many European countries and target species of various conservation efforts [8, 36, 37], the habitat potential of large-scale SRC consisting of one uniform age-class seems to be clearly limited. In general, European hares benefit from increased habitat heterogeneity, i.e. a small-scale mosaic of suitable habitats for foraging and cover with high proportions of edge-zones [36, 38-42]. Measures aimed at increasing the structural diversity of SRC, for example harvesting in sections in order to develop a mosaic of different age-classes, or integrating accompanying structures such as clearings, rides or wide headlands, could therefore improve the habitat quality of SRC for the European hare and also for other mammal species. These measures have already been recommended for other species groups such as breeding birds, small mammals, carabid beetles and vascular plants, as effective methods to increase the biodiversity value of SRC [cf. 7,43-46], and they are likely to be effective for large- and mediumsized mammals too [cf. 18]. Nevertheless, they should be systematically tested in order to verify their effectiveness for this species group and for specific species like the European hare. If their effectiveness is proven, some of these measures could be offered as mammal-specific agri-environmental schemes for SRC in order to compensate farmers for yield losses or increased management efforts.

In addition to a monotonous vegetation structure, there may also be reduced cover and species richness of the ground-layer vegetation within large-scale commercial SRC as a result of intense shading and herbicide use [4, 30]. These plantations may therefore have a reduced value as foraging habitat for herbivorous mammal species that feed on grasses and herbs (cf. Petrovan et al. [8] for Miscanthus bioenergy crops as foraging habitat for the European hare). Therefore, if possible, the use of herbicides (which is already low in SRC) should be completely avoided and replaced by mechanical measures. Aside from increasing the structural diversity of a plantation, sectional harvesting can also contribute to an improved food supply for herbivores as the weed layer regenerates after harvesting. As a result, herbivorous species like the European hare are always able to find patches of dense herbaceous vegetation within a plantation. A basic problem caused by the presence of herbivores on SRC is the risk of crop damage [15]. Under certain circumstances, such as high deer densities and unfavourable weather conditions, browsing can lead to severe damage in SRC and may require fencing, especially on smaller plantations [47, 48]. However, this leads to the exclusion of all large and medium-sized mammals from the plantations, which means that any wildlife benefits, such as cover or food supply, get completely lost for this species group. Therefore, if possible, fencing should be avoided or be restricted to the first years after establishment of a SRC. For areas with low game densities and therefore a low risk of crop damage, this can be a financially viable option, as the costs for fencing are relatively high $[2,47]$. However, if the risk of deer browsing requires fencing, then fences should be used that exclude deer species as the major damage causers [47] from the plantations, but have passages for smaller mammals like hares. From a wildlife-oriented perspective, it would be useful to provide financial support for appropriate fences, i.e. 
to compensate farmers for the cost difference in comparison to regular fencing.

Unlike for farmland and ecotone species or habitat generalists, enhancing the habitat quality of SRC for forestassociated species is difficult, since forest-specific habitat elements (e.g. old trees, tree cavities, woody debris, nut- or fruit-bearing trees) are missing in these plantations [13] and their integration into the regular crop management is hardly possible. Therefore, as for other species groups (e.g. small mammals [43, 49], breeding birds [26, 31, 50] and carabid beetles [51]), the habitat potential of SRC for forest-dwelling mammals is clearly limited $[13,18]$. This also explains the predominantly low visit frequency or even absence of more forest-associated species such as badger, pine marten or red squirrel at our study sites, despite the fact that the study sites were located in a rather forested region and that these species are quite common there. Since SRC are monotonous in comparison to other woody habitats and their succession is constantly hindered by harvesting in short cycles, they do not represent a suitable alternative to forest habitat nor play a major role as travel corridors for forest-associated mammal species [13].

\section{Appendix}

Table 5 Proportion (in \%) of species-specific detections of the total number of detections per study site and season (cumulative detections of all 3 CTs used per site; $W$ winter, $S$ summer). In brackets: total number $(n / 18)$ of CTs with detections of the particular species per season

\begin{tabular}{|c|c|c|c|c|c|c|c|c|}
\hline \multicolumn{9}{|c|}{ Study site } \\
\hline & & $\mathbf{A}$ & B & $\mathbf{C}$ & D & $\mathbf{E}$ & $\mathbf{F}$ & Total \\
\hline \multirow{2}{*}{ No. of detections } & W & 123 & 245 & 141 & 107 & 34 & 85 & 735 \\
\hline & $\mathrm{S}$ & 192 & 425 & 305 & 87 & 133 & 22 & 1,164 \\
\hline \multirow{2}{*}{ Roe deer } & $\mathrm{W}$ & 82.9 & 61.2 & 29.8 & 73.8 & 11.8 & 21.2 & $53.8(16)$ \\
\hline & $\mathrm{S}$ & 87.0 & 67.1 & 34.4 & 72.4 & 56.4 & 77.3 & $61.2(17)$ \\
\hline \multirow{2}{*}{ Wild boar } & W & 1.6 & 3.3 & 39.0 & 0.9 & 41.2 & 58.8 & $17.7(14)$ \\
\hline & $\mathrm{S}$ & 10.4 & 3.1 & 46.2 & 5.7 & 27.1 & & $18.5(10)$ \\
\hline \multirow{2}{*}{ Red fox } & $\mathrm{W}$ & 9.8 & 7.3 & 3.5 & 5.6 & 11.8 & 8.2 & $7.1(16)$ \\
\hline & $\mathrm{S}$ & 1.0 & 0.7 & 1.0 & 1.1 & 1.5 & 9.1 & $1.1(11)$ \\
\hline \multirow{2}{*}{ Europ. hare } & $\mathrm{W}$ & & 16.7 & 2.1 & 12.1 & 2.9 & & $7.9(9)$ \\
\hline & $\mathrm{S}$ & & 0.7 & 0.3 & 13.8 & 0.8 & & $1.5(7)$ \\
\hline \multirow{2}{*}{ Europ. badger } & $\mathrm{W}$ & 3.3 & 6.5 & 9.2 & & 8.8 & & $4.9(10)$ \\
\hline & $\mathrm{S}$ & 0.5 & 23.3 & & & 6.0 & & $9.3(6)$ \\
\hline \multirow{2}{*}{ Raccoon dog } & W & 0.8 & 0.4 & & & 5.9 & 5.9 & $1.2(4)$ \\
\hline & $\mathrm{S}$ & & 0.5 & 0.7 & & & & $0.3(2)$ \\
\hline \multirow{2}{*}{ Beech marten } & W & & & & 0.9 & 2.9 & & $0.3(2)$ \\
\hline & $\mathrm{S}$ & & 1.2 & 0.7 & & 0.8 & & $0.7(4)$ \\
\hline \multirow{2}{*}{ Raccoon } & W & & & 8.5 & & & & $1.6(3)$ \\
\hline & $\mathrm{S}$ & & & 1.6 & & & & $0.4(1)$ \\
\hline \multirow{2}{*}{ Fallow deer } & W & & & 6.4 & & & & $1.2(2)$ \\
\hline & $\mathrm{S}$ & 1.0 & 1.4 & 13.8 & 2.3 & & & $4.5(6)$ \\
\hline \multirow{2}{*}{ Red squirrel } & W & & & & & & & \\
\hline & $\mathrm{S}$ & & 0.2 & & & 0.8 & & $0.2(2)$ \\
\hline \multirow{2}{*}{ Europ. polecat } & W & & & & & & 1.2 & $0.1(1)$ \\
\hline & $\mathrm{S}$ & & & & & & & \\
\hline \multirow{2}{*}{ Genus Martes } & W & & & 0.7 & 3.7 & 2.9 & & $0.8(5)$ \\
\hline & $\mathrm{S}$ & & & & 1.1 & 1.5 & 4.5 & $0.3(4)$ \\
\hline \multirow{2}{*}{$\begin{array}{l}\text { Genus Martes } \\
\text { or Mustela }\end{array}$} & W & & & & & & 1.2 & $0.1(1)$ \\
\hline & $\mathrm{S}$ & & & & & 0.8 & & $0.1(1)$ \\
\hline \multirow{2}{*}{ Not determinable } & W & 1.6 & 4.5 & 0.7 & 2.8 & 11.8 & 3.5 & $3.3(13)$ \\
\hline & S & & 1.9 & 1.3 & 3.4 & 4.5 & 9.1 & $2.0(11)$ \\
\hline
\end{tabular}


Table 6 Mean values $( \pm \mathrm{SD})$ of the measured variables per $\mathrm{CT}$ in the three distance classes from the edge to the centre of the SRC (with $n=6 \mathrm{CTs}$ per distance-class) in winter. Differences between the classes were tested by Friedman test

\begin{tabular}{|c|c|c|c|c|c|}
\hline \multirow[t]{2}{*}{ Variable } & \multicolumn{3}{|c|}{ Distance-class } & \multirow[t]{2}{*}{ Test statistics } & \multirow[t]{2}{*}{$p$} \\
\hline & $5 \mathrm{~m}$ & $25 \mathrm{~m}$ & $50 \mathrm{~m}$ & & \\
\hline No. of species & $4.5 \pm 1.9$ & $4.0 \pm 1.1$ & $4.8 \pm 1.6$ & 0.700 & 0.705 n.s \\
\hline No. of species per camera day & $0.17 \pm 0.1$ & $0.22 \pm 0.22$ & $0.27 \pm 0.13$ & 3.909 & $0.142 \mathrm{n} . \mathrm{s}$ \\
\hline \multicolumn{6}{|l|}{ Visit frequency $^{\mathrm{a}}$} \\
\hline Any species & $15.6 \pm 7.9$ & $18.6 \pm 15.4$ & $24.3 \pm 10.2$ & 4.333 & $0.115 \mathrm{n} . \mathrm{s}$ \\
\hline Roe deer & $8.0 \pm 6.3$ & $9.1 \pm 11.8$ & $12.1 \pm 10.9$ & 2.348 & 0.309 n.s \\
\hline Wild boar & $1.9 \pm 1.7$ & $2.5 \pm 1.7$ & $3.7 \pm 3.0$ & 5.182 & $0.075 \mathrm{n} . \mathrm{s}$ \\
\hline Red fox & $2.2 \pm 1.7$ & $3.9 \pm 2.7$ & $4.2 \pm 1.5$ & 3.909 & $0.142 \mathrm{n} . \mathrm{s}$ \\
\hline Europ. hare & $2.2 \pm 3.3$ & $3.3 \pm 6.1$ & $2.0 \pm 2.5$ & 0.000 & $1.000 \mathrm{n.s}$ \\
\hline Europ. badger & $0.8 \pm 1.0$ & $2.2 \pm 3.1$ & $2.1 \pm 1.9$ & 4.133 & $0.127 \mathrm{n} . \mathrm{s}$ \\
\hline Raccoon dog & $0.2 \pm 0.5$ & $0.2 \pm 0.5$ & $1.1 \pm 1.9$ & 0.500 & 0.779 n.s \\
\hline Beech marten & $0.2 \pm 0.6$ & $0.2 \pm 0.5$ & $0 \pm 0$ & 1.000 & $0.607 \mathrm{n} . \mathrm{s}$ \\
\hline Raccoon & $0.2 \pm 0.5$ & $0.2 \pm 0.5$ & $0.8 \pm 2$ & 2.000 & $0.368 \mathrm{n} . \mathrm{s}$ \\
\hline Fallow deer & $0.2 \pm 0.5$ & $0 \pm 0$ & $0.6 \pm 1.5$ & 2.000 & $0.368 \mathrm{n} . \mathrm{s}$ \\
\hline European polecat & $0.2 \pm 0.5$ & $0 \pm 0$ & $0 \pm 0$ & 2.000 & $0.368 \mathrm{n} . \mathrm{s}$ \\
\hline \multicolumn{6}{|l|}{ Use intensity $^{\mathrm{b}}$} \\
\hline All species & $34.9 \pm 16.1$ & $52.9 \pm 47.6$ & $63.2 \pm 31.2$ & 4.333 & $0.115 \mathrm{n} . \mathrm{s}$ \\
\hline Roe deer & $15.6 \pm 10.7$ & $31.2 \pm 35.1$ & $32.3 \pm 27.8$ & 0.783 & $0.676 \mathrm{n} . \mathrm{s}$ \\
\hline Wild boar & $9.9 \pm 15.4$ & $5.4 \pm 4.8$ & $12.6 \pm 16.3$ & 0.095 & 0.953 n.s \\
\hline Red fox & $2.4 \pm 2.1$ & $4.5 \pm 3.8$ & $4.2 \pm 1.5$ & 2.696 & $0.260 \mathrm{n} . \mathrm{s}$ \\
\hline Europ. hare & $2.6 \pm 3.9$ & $5.7 \pm 11.9$ & $3.6 \pm 4.7$ & 0.571 & $0.751 \mathrm{n} . \mathrm{s}$ \\
\hline Europ. badger & $1.0 \pm 1.2$ & $3.2 \pm 4.5$ & $3.1 \pm 2.8$ & 3.500 & 0.174 n.s \\
\hline Raccoon dog & $0.2 \pm 0.5$ & $0.2 \pm 0.5$ & $1.5 \pm 2.5$ & 0.500 & $0.779 \mathrm{n.s}$ \\
\hline Beech marten & $0.2 \pm 0.6$ & $0.2 \pm 0.5$ & $0 \pm 0$ & 1.000 & $0.607 \mathrm{n} . \mathrm{s}$ \\
\hline Raccoon & $0.2 \pm 0.5$ & $0.6 \pm 1.5$ & $1.6 \pm 3.9$ & 2.000 & $0.368 \mathrm{n.s}$ \\
\hline Fallow deer & $0.4 \pm 1.0$ & $0 \pm 0$ & $1.4 \pm 3.4$ & 2.000 & $0.368 \mathrm{n} . \mathrm{s}$ \\
\hline European polecat & $0.2 \pm 0.5$ & $0 \pm 0$ & $0 \pm 0$ & 2.000 & $0.368 \mathrm{n.s}$ \\
\hline
\end{tabular}

n.s. not significant; ${ }^{*} p<0.05$

${ }^{\mathrm{a}} \mathrm{Visit}$ frequency $=$ proportion of days [\%] with presence per CT

${ }^{\mathrm{b}}$ Use intensity $=$ no. of detections per 100 camera days per CT 
Table 7 Mean values $( \pm \mathrm{SD})$ of the measured variables per $\mathrm{CT}$ in the three distance classes from the edge to the centre of the SRC (with $n=6$ CTs per distance-class) in summer. Differences between the classes were tested by Friedman-test

\begin{tabular}{|c|c|c|c|c|c|}
\hline \multirow[t]{2}{*}{ Variable } & \multicolumn{3}{|l|}{ Distance-class } & \multirow[t]{2}{*}{ Test statistics } & \multirow[t]{2}{*}{$p$} \\
\hline & $5 \mathrm{~m}$ & $25 \mathrm{~m}$ & $50 \mathrm{~m}$ & & \\
\hline No. of species & $4.0 \pm 2.0$ & $3.5 \pm 1.9$ & $4.2 \pm 1.5$ & 1.810 & $0.405 \mathrm{n} . \mathrm{s}$ \\
\hline No. of species per camera day & $0.29 \pm 0.25$ & $0.25 \pm 0.24$ & $0.28 \pm 0.26$ & 1.652 & $0.438 \mathrm{n} . \mathrm{s}$ \\
\hline \multicolumn{6}{|l|}{ Visit frequency $^{\mathrm{a}}$} \\
\hline Any species & $25.0 \pm 20.9$ & $22.2 \pm 19.9$ & $24.4 \pm 21.5$ & 1.652 & $0.438 \mathrm{n} . \mathrm{s}$ \\
\hline Roe deer & $16.5 \pm 16.1$ & $11.0 \pm 10.3$ & $11.9 \pm 11.2$ & 0.333 & $0.846 \mathrm{n} . \mathrm{s}$ \\
\hline Wild boar & $2.6 \pm 4.4$ & $2.7 \pm 5.2$ & $4.9 \pm 3.4$ & 2.842 & $0.241 \mathrm{n} . \mathrm{s}$ \\
\hline Red fox & $2.0 \pm 1.2$ & $0.5 \pm 0.8$ & $1.1 \pm 0.8$ & 3.125 & $0.210 \mathrm{n} . \mathrm{s}$ \\
\hline Europ. hare & $1.1 \pm 2.0$ & $0.8 \pm 0.9$ & $1.1 \pm 1.7$ & 0.143 & $0.931 \mathrm{n} . \mathrm{s}$ \\
\hline Europ. badger & $2.7 \pm 4.6$ & $5.6 \pm 12.3$ & $5.4 \pm 12.4$ & 0.200 & $0.905 \mathrm{n} . \mathrm{s}$ \\
\hline Raccoon dog & $0 \pm 0$ & $0.6 \pm 0.9$ & $0 \pm 0$ & 4.000 & 0.135 n.s \\
\hline Beech marten & $0.8 \pm 1.3$ & $0.3 \pm 0.8$ & $0.3 \pm 0.7$ & 1.400 & 0.497 n.s \\
\hline Raccoon & $0 \pm 0$ & $0 \pm 0$ & $0.3 \pm 0.7$ & 2.000 & $0.368 \mathrm{n} . \mathrm{s}$ \\
\hline Fallow deer & $1.4 \pm 3.3$ & $1.3 \pm 2.4$ & $1.9 \pm 2.6$ & 1.077 & 0.584 n.s \\
\hline Red squirrel & $0.5 \pm 0.8$ & $0 \pm 0$ & $0 \pm 0$ & 4.000 & $0.135 \mathrm{n} . \mathrm{s}$ \\
\hline \multicolumn{6}{|l|}{ Use intensity ${ }^{\mathrm{b}}$} \\
\hline All species & $108.2 \pm 88.6$ & $75.6 \pm 57.6$ & $144.3 \pm 125.8$ & 4.333 & $0.115 \mathrm{n} . \mathrm{s}$ \\
\hline Roe deer & $83.3 \pm 71.3$ & $36.9 \pm 28.0$ & $80.6 \pm 93.0$ & 2.333 & $0.311 \mathrm{n} . \mathrm{s}$ \\
\hline Wild boar & $5.8 \pm 7.2$ & $10.5 \pm 16.9$ & $42.6 \pm 86.1$ & 0.316 & 0.854 n.s \\
\hline Red fox & $2.0 \pm 1.2$ & $0.5 \pm 0.8$ & $1.1 \pm 0.8$ & 3.125 & $0.210 \mathrm{n} . \mathrm{s}$ \\
\hline Europ. hare & $3.9 \pm 8.9$ & $0.8 \pm 0.9$ & $1.7 \pm 2.9$ & 0.143 & 0.931 n.s \\
\hline Europ. badger & $6.5 \pm 12.3$ & $13.2 \pm 30.0$ & $9.4 \pm 22.3$ & 0.182 & 0.913 n.s \\
\hline Raccoon dog & $0 \pm 0$ & $1.2 \pm 1.9$ & $0 \pm 0$ & 4.000 & $0.135 \mathrm{n} . \mathrm{s}$ \\
\hline Beech marten & $1.1 \pm 1.9$ & $0.7 \pm 1.6$ & $0.5 \pm 1.3$ & 1.400 & 0.497 n.s \\
\hline Raccoon & $0 \pm 0$ & $0 \pm 0$ & $1.4 \pm 3.3$ & 2.000 & 0.368 n.s \\
\hline Fallow deer & $3.2 \pm 7.9$ & $8.0 \pm 15.2$ & $4.6 \pm 7$ & 1.077 & $0.584 \mathrm{n} . \mathrm{s}$ \\
\hline Red squirrel & $0.5 \pm 0.8$ & $0 \pm 0$ & $0 \pm 0$ & 4.000 & $0.135 \mathrm{n} . \mathrm{s}$ \\
\hline
\end{tabular}

n.s. not significant; $* p<0.05$

${ }^{\mathrm{a}} \mathrm{Visit}$ frequency $=$ proportion of days [\%] with presence per CT

${ }^{\mathrm{b}}$ Use intensity $=$ no. of detections per 100 camera days per CT

\begin{abstract}
Acknowledgements We are grateful to the farmers for giving us access to their plantations. We thank M. Senne and M. Züchner for their assistance in field work. We are also grateful to L. von Falkenhayn for proofreading the English manuscript and to both anonymous reviewers who made valuable and helpful comments on an earlier version of the manuscript.
\end{abstract}

Funding Open Access funding enabled and organized by Projekt DEAL.

Availability of Data and Material The raw-datasets generated during and/or analysed during the current study are available from the corresponding author on reasonable request.

Code Availability Not applicable.

\section{Declarations}

Ethics Approval Not applicable.

Conflict of Interest The authors declare no competing interests.
Open Access This article is licensed under a Creative Commons Attribution 4.0 International License, which permits use, sharing, adaptation, distribution and reproduction in any medium or format, as long as you give appropriate credit to the original author(s) and the source, provide a link to the Creative Commons licence, and indicate if changes were made. The images or other third party material in this article are included in the article's Creative Commons licence, unless indicated otherwise in a credit line to the material. If material is not included in the article's Creative Commons licence and your intended use is not permitted by statutory regulation or exceeds the permitted use, you will need to obtain permission directly from the copyright holder. To view a copy of this licence, visit http://creativecommons.org/licenses/by/4.0/.

\section{References}

1. Landgraf D, Bärwolff M, Burger F (2018) Produktivität, Management und Nutzung von Agrarholz. In: Veste M, Böhm C (eds) Agrarholz-Schnellwachsende Bäume in der Landwirtschaft. Springer, Berlin, Heidelberg, pp 447-510. https://doi.org/10.1007/ 978-3-662-49931-3_14 
2. Dimitriou I, Rutz D (eds) (2015) Sustainable short rotation coppice. A Handbook. WIP Renewable Energies, München. https:// www.srcplus.eu/images/Handbook_SRCplus.pdf. Accessed 25 Apr 2021

3. Veste M, Schillem S, Böhm C (2018) Baumarten für die Agrarholzproduktion. In: Veste M, Böhm C (eds) Agrarholz-Schnellwachsende Bäume in der Landwirtschaft. Springer, Berlin, Heidelberg, pp 81-118. https://doi.org/10.1007/978-3-662-499313_4

4. Sage RB (1998) Short rotation coppice for energy. Towards ecological guidelines. Biomass Bioenergy 15:39-47. https://doi.org/ 10.1016/S0961-9534(97)10055-1

5. Anderson GQA, Fergusson MJ (2006) Energy from biomass in the UK: sources, processes and biodiversity implications. Ibis 148:180-183. https://doi.org/10.1111/j.1474-919X.2006.00535.x

6. Dauber J, Jones MB, Stout JC (2010) The impact of biomass crop cultivation on temperate biodiversity. Glob Change Biol Bioenergy 2:289-309. https://doi.org/10.1111/j.1757-1707.2010. 01058.x

7. Sage R, Cunningham M, Boatman N (2006) Birds in willow shortrotation coppice compared to other arable crops in central England and a review of bird census data from energy crops in the UK. Ibis 148:184-197. https://doi.org/10.1111/j.1474-919X.2006.00522.x

8. Petrovan SO, Dixie J, Yapp E, Wheeler PM (2017) Bioenergy crops and farmland biodiversity: benefits and limitations are scaledependant for a declining mammal, the brown hare. Eur J Wildl Res 63.https://doi.org/10.1007/s10344-017-1106-5

9. Pedroli B, Elbersen B, Frederiksen P, Grandin U, Heikkilä R, Krogh PH, Izakovičová Z, Johansen A, Meiresonne L, Spijker J (2013) Is energy cropping in Europe compatible with biodiversity?-Opportunities and threats to biodiversity from land-based production of biomass for bioenergy purposes. Biomass Bioenergy 55:73-86. https://doi.org/10.1016/j.biombioe.2012.09.054

10. Baum S, Weih M, Busch G, Kroiher F, Bolte A (2009) The impact of short rotation coppice plantations on phytodiversity. Appl Agric Forestry Res 59:163-170

11. Vanbeveren SPP, Ceulemans R (2019) Biodiversity in short-rotation coppice. Renew Sust Energ Rev 111:34-43. https://doi.org/ 10.1016/j.rser.2019.05.012

12. Rowe RL, Street NR, Taylor G (2009) Identifying potential environmental impacts of large-scale deployment of dedicated bioenergy crops in the UK. Renew Sust Energ Rev 13:271-290. https:// doi.org/10.1016/j.rser.2007.07.008

13. Christian DP (1997) Wintertime use of hybrid poplar plantations by deer and medium-sized mammals in the midwestern U.S. Biomass Bioenergy 12:35-40. https://doi.org/10.1016/S09619534(96)00062-1

14. Sage R, Tucker K (1998) Integrated crop management of SRC plantations to maximise crop value, wildlife benefits and other added value opportunities. Technical report B/W2/00400/REP, funded by the energy technology support unit and the Department of Trade and Industry. Harwell. https://www.osti.gov/etdew eb/servlets/purl/20015940. Accessed 17 May 2021

15. Bergström R, Guillet C (2002) Summer browsing by large herbivores in short-rotation willow plantations. Biomass Bioenergy 23:27-32. https://doi.org/10.1016/S0961-9534(02)00027-2

16. Schulz U, Gruß H, Hofmann V (2008) Wirbeltiere (Säugetiere und Brutvögel) auf Agrarholzflächen - erste Ergebnisse aus dem Projekt NOVALIS. Cottbuser Schriften zur Ökosystemgenese u Landschaftsentwicklung 6:167-169

17. Fry D, Slater F (2009) The biodiversity of short rotation willow coppice in the Welsh landscape. https://www.aber.ac.uk/en/media/ departmental/ibers/research/willowforwales/Biodiversity-of-srccoppice-in-the-Welsh-Landscape.pdf. Accessed 01 May 2021

18. Zitzmann F, Reich M, Schaarschmidt F (2021) Potential of smallscale and structurally diverse short-rotation coppice as habitat for large and medium-sized mammals. Biologia 76:2195-2206. https://doi.org/10.1007/s11756-021-00686-0

19. Englund O, Dimitriou I, Dale VH, Kline KL, Mola-Yudego B, Murphy F, English B, McGrath J, Busch G, Negri MC, Brown M, Goss K, Jackson S, Parish ES, Cacho J, Zumpf C, Quinn J, Mishra SK (2020) Multifunctional perennial production systems for bioenergy: performance and progress. WIREs Energy Environ (e375). https://doi.org/10.1002/wene.375

20. LSN (2018) Statistische Berichte Niedersachsen - Bodenflächen in Niedersachsen nach Art der tatsächlichen Nutzung 2016, Hannover. https://www.statistik.niedersachsen.de/startseite/themen/ gebiet_flachennutzung/flachennutzung_in_niedersachsen/flach ennutzung-in-niedersachsen-statistische-berichte-87671.html. Accessed 14 April 2021

21. Burton AC, Neilson E, Moreira D, Ladle A, Steenweg R, Fisher JT, Bayne E, Boutin S (2015) Wildlife camera trapping: a review and recommendations for linking surveys to ecological processes. J Appl Ecol 52:675-685. https://doi.org/10.1111/1365-2664. 12432

22. O'Connell AF, Nichols JD, Karanth KU (eds) (2011) Camera traps in animal ecology: methods and analyses. Springer, Tokyo. https://doi.org/10.1007/978-4-431-99495-4

23. Armenteros JA, Caro J, Sanchez-Garcia C, Arroyo B, Perez JA, Gaudioso VR, Tizado EJ (2020) Do non-target species visit feeders and water troughs targeting small game? A study from farmland Spain using camera-trapping. Integrative Zoology 0:1-14. https://doi.org/10.1111/1749-4877.12496

24. Greiser G, Krüger S, Martin I, Thelke F (2020) Status und Entwicklung ausgewählter Wildtierarten in Deutschland. Jahresbericht 2018. Wildtier-Informationssystem der Länder Deutschlands (WILD), Berlin. https://www.jagdverband.de/ sites/default/files/2020-01_Broschuere_WILD-Bericht_2018. pdf. Accessed 6 April 2021

25. Meinig H, Boye P, Dähne M, Hutterer R, Lang J (2020) Rote Liste und Gesamtartenliste der Säugetiere (Mammalia) Deutschlands. Naturschutz und Biologische Vielfalt, 170 (2), Münster. https:// www.bfn.de/fileadmin/BfN/roteliste/Dokumente/NaBiV_170_2_ Rote_Liste_Saeugetiere.pdf. Accessed 12 March 2021

26. Berg $\AA$ (2002) Breeding birds in short-rotation coppices on farmland in central Sweden - the importance of Salix height and adjacent habitats. Agric Ecosyst Environ 90:265-276. https://doi.org/ 10.1016/S0167-8809(01)00212-2

27. Baum S, Bolte A, Weih M (2012) High value of short rotation coppice plantations for phytodiversity in rural landscapes. Glob Change Biol Bioenergy 4:728-738. https://doi.org/10.1111/j. 1757-1707.2012.01162.x

28. Baum S, Bolte A, Weih M (2012) Short rotation coppice (SRC) plantations provide additional habitats for vascular plant species in agricultural mosaic landscapes. BioEnergy Res 5:573-583. https://doi.org/10.1007/s12155-012-9195-1

29. Weih M, Karacic A, Munkert H, Verwijst T, Diekmann M (2003) Influence of young poplar stands on floristic diversity in agricultural landscapes (Sweden). Basic Appl Ecol 4:149-156. https:// doi.org/10.1078/1439-1791-00157

30. Cunningham MD, Bishop JD, McKay HV, Sage RB (2004) ARBRE monitoring - ecology of short rotation coppice. Four year study involving wildlife monitoring of commercial SRC plantations planted on arable land and arable control plots. Technical report B-U-1/00627/REP; DTI-PUB-URN-04/961, funded by the Department of Trade and Industry, London. https://www.osti.gov/ etdeweb/servlets/purl/20496469. Accessed 15 March 2021

31. Gruß H, Schulz U (2011) Brutvogelfauna auf Kurzumtriebsplantagen. Besiedlung und Habitateignung verschiedener Strukturtypen. Naturschutz und Landschaftsplanung 43:197-204

32. Rowe RL, Hanley ME, Goulson D, Clarke DJ, Doncaster CP, Taylor G (2011) Potential benefits of commercial willow short 
rotation coppice (SRC) for farm-scale plant and invertebrate communities in the agri-environment. Biomass Bioenergy 35:325336. https://doi.org/10.1016/j.biombioe.2010.08.046

33. Kriegel P, Fritze M-A, Thorn S (2021) Surface temperature and shrub cover drive ground beetle (Coleoptera: Carabidae) assemblages in short-rotation coppices. Agric For Entomol. https://doi. org/10.1111/afe.12441

34. Strauß E, Grauer A, Bartel M, Klein R, Wenzelides L, Greiser G, Muchin A, Nösel H, Winter A (2008) The German wildlife information system: population densities and development of European Hare (Lepus europaeus PALLAS) during 2002-2005 in Germany. Eur J Wildl Res 54:142-147. https://doi.org/10.1007/ s10344-007-0112-4

35. Sliwinski K, Ronnenberg K, Jung K, Strauß E, Siebert U (2019) Habitat requirements of the European brown hare (Lepus europaeus Pallas 1778) in an intensively used agriculture region (Lower Saxony, Germany). BMC Ecol 19:1-11. https://doi.org/ 10.1186/s12898-019-0247-7

36. Smith RK, Jennings NV, Robinson A, Harris S (2004) Conservation of European hares Lepus europaeus in Britain: is increasing habitat heterogeneity in farmland the answer? J Appl Ecol 41:1092-1102. https://doi.org/10.1111/j.0021-8901.2004.00976.x

37. Macdonald DW, Tattersall FH, Service KM, Firbank LG, Feber RE (2007) Mammals, agri-environment schemes and set-asidewhat are the putative benefits? Mammal Rev 37:259-277. https:// doi.org/10.1046/j.1440-1770.2002.00172_37_4.x

38. Schai-Braun SC, Ruf T, Klansek E, Arnold W, Hackländer K (2020) Positive effects of set-asides on European hare (Lepus europaeus) populations: leverets benefit from an enhanced survival rate. Biol Conserv 244:108518. https://doi.org/10.1016/j. biocon.2020.108518

39. Mayer M, Ullmann W, Sunde P, Fischer C, Blaum N (2018) Habitat selection by the European hare in arable landscapes: the importance of small-scale habitat structure for conservation. Ecol Evol 8:11619-11633. https://doi.org/10.1002/ece3.4613

40. Voigt U, Siebert U (2019) Living on the edge-circadian habitat usage in pre-weaning European hares (Lepus europaeus) in an intensively used agricultural area. PLoS ONE 14:e0222205. https://doi.org/10.1371/journal.pone.0222205

41. Voigt U, Siebert U (2020) Survival rates on pre-weaning European hares (Lepus europaeus) in an intensively used agricultural area. Eur J Wildl Res 66:1-12. https://doi.org/10.1007/ s10344-020-01403-Z
42. Johann F, Arnold J (2021) Scattered woody vegetation promotes European brown hare population. Basic Appl Ecol 56:322-334. https://doi.org/10.1016/j.baae.2021.08.012

43. Christian DP, Collins PT, Hanowski JM, Niemi GJ (1997) Bird and small mammal use of short-rotation hybrid poplar plantations. J Wildl Manage 61:171-182. https://doi.org/10.2307/3802426

44. Gustafsson L (1987) Plant conservation aspects of energy forestrya new type of land use in Sweden. For Ecol Manag 21:141-161. https://doi.org/10.1016/0378-1127(87)90078-8

45. Hanowski JM, Niemi GJ, Christian DC (1997) Influence of withinplantation heterogeneity and surrounding landscape composition on avian communities in hybrid poplar plantations. Conserv Biol 11:936-944. https://doi.org/10.1046/j.1523-1739.1997.96173.x

46. Moser BW, Pipas MJ, Witmer GW, Engeman RM (2002) Small mammal use of hybrid poplar plantations relative to stand age. Northwest Sci 76:158-165

47. Landgraf D, Brunner J, Helbig C (2011) The impact of wild animals on SRC in Germany - a widely underestimated factor. In: Benwood Project Consortium (ed) BENWOOD conference proceedings: Short Rotation Forestry and Agroforestry: an Exchange of Experience between CDM Countries and Europe, pp 133-140. https://doi.org/10.13140/2.1.4942.9126

48. Helbig C, Müller M (2009) Abiotische und biotische Schadfaktoren in Kurzumtriebsplantagen. In: Reeg T, Bemmann A, Konold W, Murach D, Spiecker H (eds) Anbau und Nutzung von Bäumen auf landwirtschaftlichen Flächen. Wiley, Weinheim, pp 83-97

49. Christian DP, Hoffman W, Hanowski JM, Niemi GJ, Beyea J (1998) Bird and mammal diversity on woody biomass plantations in North America. Biomass Bioenergy 14:395-402. https:// doi.org/10.1016/S0961-9534(97)10076-9

50. Porro Z, Odicino M, Bogliani G, Chiatante G (2021) Intensive forestry and biodiversity: use of poplar plantations by woodpeckers in a lowland area of Northern Italy. For Ecol Manag 497.https:// doi.org/10.1016/j.foreco.2021.119490

51. Allegro G, Sciaky R (2003) Assessing the potential role of ground beetles (Coleoptera, Carabidae) as bioindicators in poplar stands, with a newly proposed ecological index (FAI). For Ecol Manag 175:275-284. https://doi.org/10.1016/S0378-1127(02)00135-4

Publisher's Note Springer Nature remains neutral with regard to jurisdictional claims in published maps and institutional affiliations. 